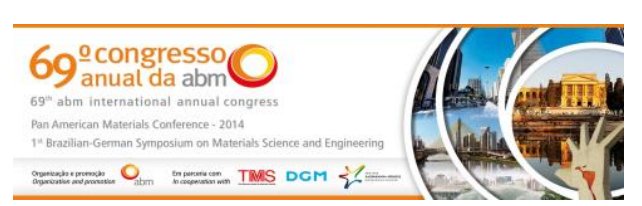

Theme: Ceramic, composite and polymeric materials

\title{
CARBON NANOTUBE REINFORCED AA6061 ALLOY FOR HIGH STRENGTH-LOW DENSITY STRUCTURAL APPLICATIONS*
}

\author{
Dilermando Nagle Travessa ${ }^{1}$ \\ Matheus Pianassola ${ }^{2}$ \\ Mirian Glicea Socuta Carneiro ${ }^{3}$ \\ Kátia Regina Cardoso ${ }^{4}$ \\ Marcela Lieblich ${ }^{5}$
}

\begin{abstract}
High strength-light weight materials are very attractive for the transportation sector, particularly to the aerospace industry. High strength-age hardenable aluminium alloys are widely used in airframes due to their unique combination of strength, density, toughness, corrosion resistance, cost and easy processing. However, the hardening capacity of such alloys is somehow saturated due to thermodynamic issues related to the conventional processing. The production of aluminum-matrix composites is a promising strategy to overcome this limitation, resulting in strength levels that cannot be reached by actual commercial aluminum alloys. In the present work, multiwall carbon nanotubes were used to reinforce the AA6061 aluminium alloy. 1 and $2 \%$ weight percent of MWCNT were mixed to the alloy powder by highenergy ball-milling process. The blended powder was consolidated by hot extrusion. The obtained composite bars were submitted to heat treatment for the T6 condition in order to combine both CNT dispersion and precipitation hardening effects. Optical and scanning electron microscopy, as well as hardeness testing, was used to characterize the bars. Typical wrought microstructure, free of defects, was observed on the extruded bars. Hardness of the composites was observed to increase by 20 , 28 and $68 \%$ for $1 \%$ MWCNT $6 \mathrm{~h}$ milling, $2 \%$ MWCNT $6 \mathrm{~h}$ milling and $2 \%$ MWCNT 10 $\mathrm{h}$ milling, respectively, in the as-extruded condition. The better performance for the composites blended at higher milling time was attributed to a better nanotubes dispersion. Subsequent heat treatment to the T6 condition did not result in additional hardening.
\end{abstract}

Keywords: Carbon nanotubes; Aluminum matrix composites; AA6061 alloy; Powder metallurgy.

1 PhD, Professor, Instituto de Ciência e Tecnologia, Universidade Federal de São Paulo, São José dos Campos, São Paulo, Brazil.

2 Undergraduate student, Instituto de Ciência e Tecnologia, Universidade Federal de São Paulo, São José dos Campos, São Paulo, Brazil.

3 Graduate student, Instituto de Ciência e Tecnologia, Universidade Federal de São Paulo, São José dos Campos, São Paulo, Brazil.

4 PhD, Professor, Instituto de Ciência e Tecnologia, Universidade Federal de São Paulo, São José dos Campos, São Paulo, Brazil.

5 PhD, Researcher, Centro Nacional de Investigaciones Metalurgicas (CENIM), Consejo Superior de Investigaciones Cientificas (CSIC), Madrid, Spain.

\footnotetext{
* Technical contribution to the $69^{\text {th }}$ ABM International Annual Congress and to the ENEMET, July $21^{\text {st }}-25^{\text {th }}$, 2014, São Paulo, SP, Brazil.
} 


\section{INTRODUCTION}

Over the past seventy years, aluminum alloys have dominated the market for the aerospace industry, due to a set of intrinsic properties and characteristics, as mechanical and corrosion strength, low density, easy processing and moderate cost. However, in the latest decades, the strength level of the commercial Al alloys seems to be stalled at around $600 \mathrm{MPa}$ of ultimate strength, and conventional thermomechanical processing seems to be unable to reverse this picture.

Carbon nanotubes (CNT) is an emerging and promising class of material, exhibiting very interesting properties, among them, high strength and elastic modulus $[1,2]$. With nanometer dimensions, carbon nanotubes can be added to a set of ductile metallic materials in order to increase their strength by several mechanisms: stress fields at the metallic reticulate, Orowan, and the classic load-transfer mechanism of composite materials [3]. However, as their dimensions are nanometric, van der Waals forces promotes their agglomeration and make very challenging their homogeneous dispersion in composite materials.

High energy ball milling (HEBM) has been the most used route to produce CNT reinforced aluminum matrix composites (CNT-AMC), although the energy of the process could be deleterious to the reinforce phase integrity. Fragmentation and amorphization are the main risks to which HEBMilled CNT are subject [4]. However, it is believed that the ductile aluminum particles can hold the CNT particles at initial milling stages, protecting them from direct impacts from the milling media. As a result, several authors have reported success on CNT dispersion in aluminum by this process, keeping their structural integrity [5-8].The final consolidation of the composites produced by HEBM can obtained by several processes: hot extrusion, cold or hot pressing followed by conventional sintering, spark plasma sintering, cold or hot milling and plasma spraying are examples.

Most of the literature regarding the production of CNT-AMC is related to pure aluminum and a maximum of $5 \%$ by weight of the reinforcing phase $[5-6,8,9-15]$. Few works are related to precipitation hardenable aluminum alloys, more specifically to AA2024 [7,16-17], and the combined effect of precipitation hardening and CNT to the composite strength is rarely evaluated. Kondoh and co-workers [18] investigated the effect of the heat treatment on the AA6063 alloy reinforced by multi wall carbon nanotubes (MWCNT) produced by spark plasma sintering and hot extrusion, and observed that after aging to T6 condition both yield and ultimate tensile strength decreased, when comparing to the as-extruded condition. The authors argue that $\mathrm{Mg}$ matrix depletion, as a consequence of $\mathrm{Al}_{2} \mathrm{MgC}_{2}, \mathrm{MgO}$ and/or $\mathrm{MgAl}_{2} \mathrm{O}_{4}$ formation around nanotubes, are responsible for the unsuccessful heat treatment. Less $\mathrm{Mg}$ atoms would be available for $\mathrm{Mg}_{2} \mathrm{Si}$ hardening precipitation.

In the present work, the effect of 1 and $2 \%$ (in weight) of MWCNT reinforcing AA6061 AMC was evaluated by microhardness measurements, in the as extruded condition and after solution heat treatment followed by natural and artificial aging (T4 and T6 tempers, respectively). Optical and scanning electron microscopy were also employed to assess the microstructural development. AA6061 bars with no MWCNT reinforcement were also produced by the same processing route, for comparison purposes. It was found that the hardness was significantly increased after the addition of MWCNT to the alloy, in the asextruded condition. However, subsequent heat treatment did not provide additional hardening for both unreinforced and reinforced material, when comparing to the as-extruded condition. Possible reasons for such behavior are discussed.

\section{MATERIAL AND METHODS}

AA6061 alloy powder, produced by inert gas atomization by ALPOCO - United Kingdom and having particles lesser than $50 \mu \mathrm{m}$, was employed in the present work. The nominal chemical composition of the alloy that complies with AMS-QQ-A-200/8 specification [19], is shown in Table 1.

\footnotetext{
* Technical contribution to the $69^{\text {th }}$ ABM International Annual Congress and to the ENEMET, July $21^{\text {st }}-25^{\text {th }}, 2014$, São Paulo, SP, Brazil.
} 


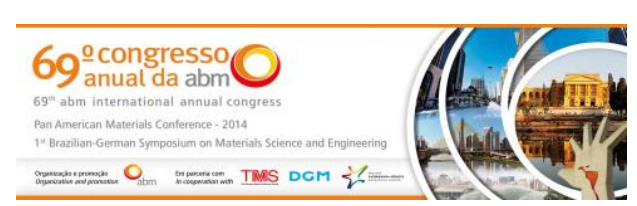

Table 1.Nominal chemical composition of AA6061 alloy used in the present work

\begin{tabular}{lc}
\hline Element & Weigth \% \\
\hline $\mathrm{Si}$ & 0,45 \\
\hline $\mathrm{Mg}$ & 0,96 \\
\hline $\mathrm{Cu}$ & 0,27 \\
\hline $\mathrm{Cr}$ & 0,16 \\
\hline $\mathrm{Fe}$ & 0,15 \\
\hline $\mathrm{Mn}$ & 0,0023 \\
\hline $\mathrm{Al}$ & $\mathrm{Bal}$ \\
\hline
\end{tabular}

Bundles of MWCNT (Baytubes ${ }^{\circledR}$ C150P) produced by chemical vapor deposition process by Bayer Materials Science - Germany, with a minimum purity level of $95 \%$, were employed as reinforcing phase. Figure 1 shows a transmission electron micrography of a typical isolated nanotube, were an aspect ratio of around 100 can be observed.

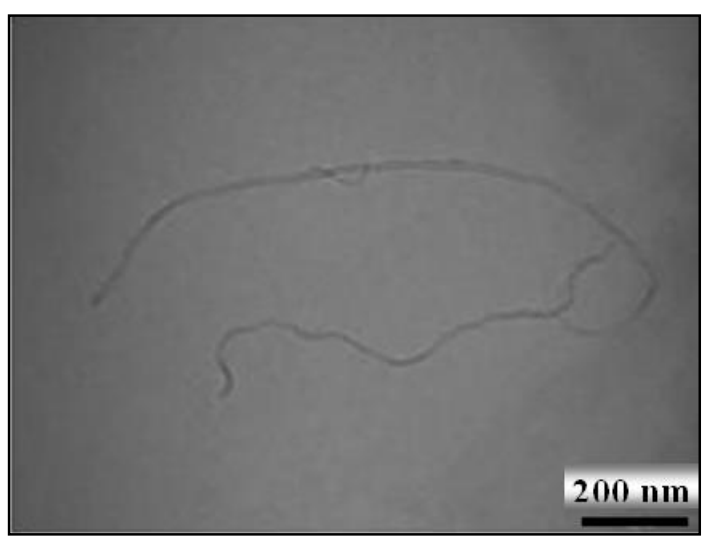

Figure 1. Aspect of isolated Baytubes $\AA^{\circledR}$ C150P, after ultrasonically assisted dissolution in acetone. For observation at the microscope, the MWCNT were captured from the solution by a carbon film covered Cu grid.

The AA6061 powder and the MWCNT were blended into a planetary ball mill Retsch PM4 in air atmosphere, using $250 \mathrm{~cm}^{3}$ stainless steel vials and $20 \mathrm{~mm}$ diameter hard steel balls. A ball to powder ratio of 10:1 at 200 RPM were employed and $0,5 \%$ in weight of stearic acid was employed as the process control agent (PCA). Composites having 1 and $2 \%$ in weight of MWCNT were produced. For comparison purpose, bars without reinforcement were also produced employing the same milling conditions. Milling times of 6 and $10 \mathrm{~h}$ were employed. For the composite milled for $10 \mathrm{~h}$, the aluminum powder, bundles of MWCNT and PCA were simply loaded into the vials. For the composite milled for $6 \mathrm{~h}$, a special mixing procedure was performed before loading into the milling vials. MWCNT was previously dispersed into acetone for $0,25 \mathrm{~h}$ under sonication. The AA6061 powder was added to this suspension with additional sonication for $0,25 \mathrm{~h}$. The mixture was subsequently heated under magnetic agitation until a thick slurry was obtained. Final drying at $50^{\circ} \mathrm{C}$ for $24 \mathrm{~h}$ was performed before adding the mixture to the milling vials, with the PCA and balls. The Table 2 resumes the main process parameters employed to obtain the composite powders.

Raman spectroscopy was performed on samples containing $2 \%$ of MWCNT in order to assess their structural quality after milling, when comparing to the pristine condition. A micro-Raman Renishaw microscope system 2000, employing an argon laser (514.5 nm wavelength) was employed on this characterization.

\footnotetext{
* Technical contribution to the $69^{\text {th }}$ ABM International Annual Congress and to the ENEMET, July $21^{\text {st }}-25^{\text {th }}$, 2014, São Paulo, SP, Brazil.
} 


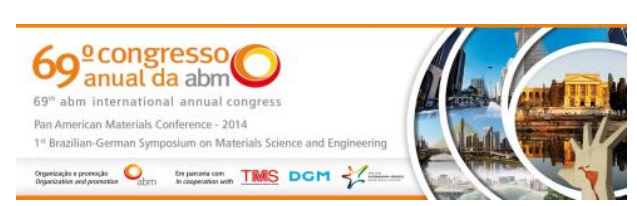

sort of contamination probably from the milling media. Figure 4 shows the microstructure of the sample 6061-2CNT-10h in T4 condition, that is representative for all bars at both T4 and T6 heat treated conditions. This microstructure shows great similarity with the bars in the as-extruded condition, although visible $\mathrm{Fe}_{3} \mathrm{SiAl}_{12}$ and $\mathrm{Mg}_{2} \mathrm{Si}$ precipitates seem to be less abundant. This is consistent with the heat treated condition that dissolves much of these precipitates that re-precipitates in a smaller size during aging. From Figure 4, it is also possible to verify some voids arising after heat treatment. These voids, indicated by arrows at the Figure 4, are aligned to the extrusion direction and can result from the expansion of entrapped gases, during solution heat treatment.

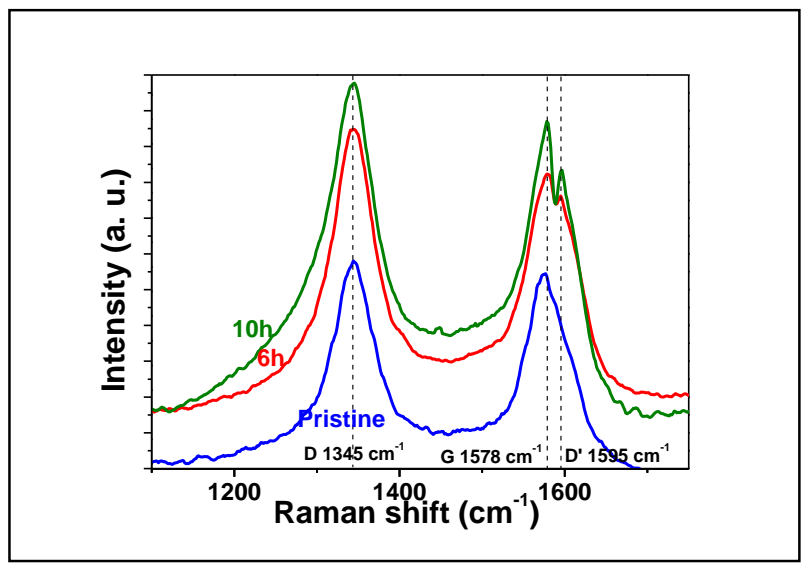

Figure 2. Raman spectroscopy of the samples containing 2\% (weight) of MWCNT, after milling for 6 and $10 \mathrm{~h}$. A spectrum from the isolated nanotubes in the as-received condition is also presented for comparison purpose.
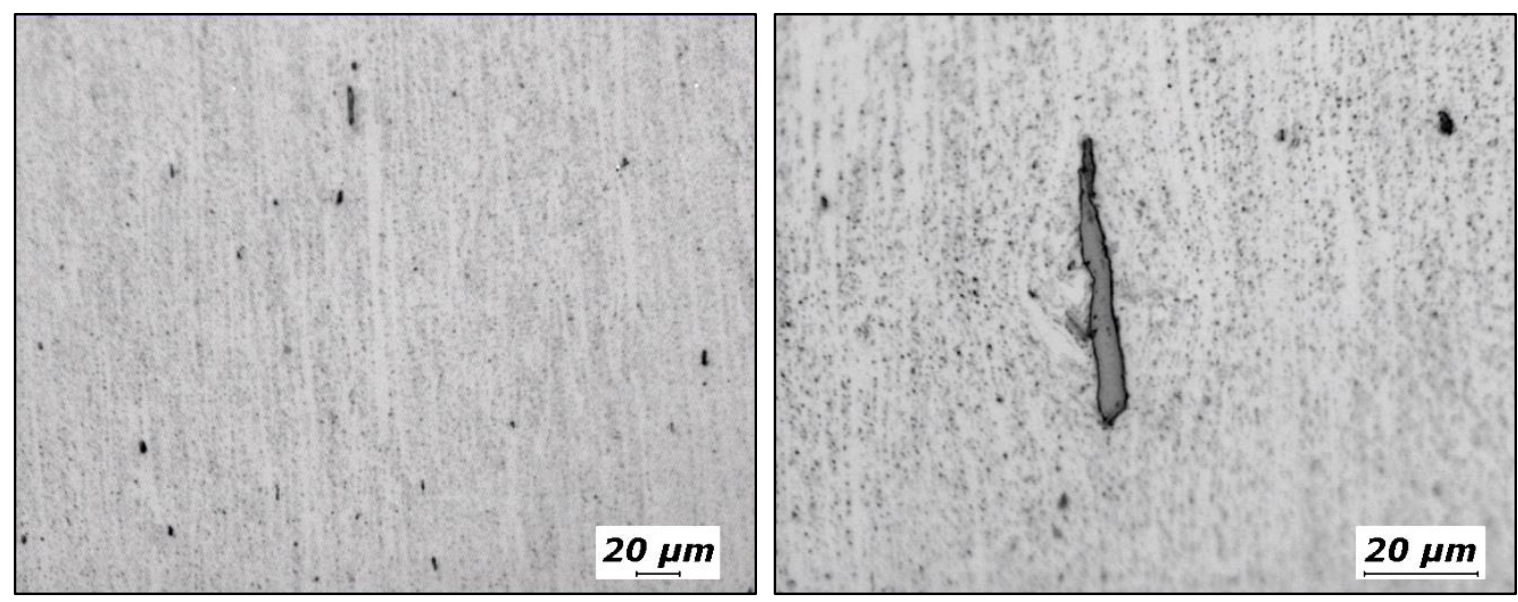

Figure 3. Optical micrographs of samples containing $2 \%$ of MWCNT milled for $6 \mathrm{~h}$ (6061-2CNT-6h), in the longitudinal as-extruded condition: 3A- overall aspect showing fine precipitation; 3B- higher magnification showing extrusion lines around a bigger particle.

Scanning electron microscopy performed on the sample 6061-NR-6h shows in detail (Figure 5) one particle that is similar to the bigger particles mentioned in the Figure 3B. Quantitative microanalysis performed resulted in a composition similar to $3 \mathrm{XX}$ series austenitic stainless steel, confirming that such particles are contaminants from the milling media (vials).

The results from microhardness testing preformed on samples in the as-extruded, T4 and T6 conditions are presented in Table 3 and Figure 6 . It can be easily observed the contribution of MWCNT additions to the hardness of the bars. This contribution is

\footnotetext{
* Technical contribution to the $69^{\text {th }}$ ABM International Annual Congress and to the ENEMET, July $21^{\text {st }}-25^{\text {th }}$, 2014, São Paulo, SP, Brazil.
} 


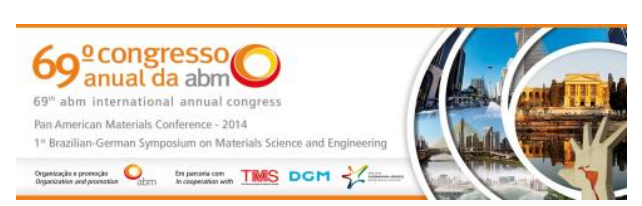

higher as the CNT content increases from 1 to $2 \%$ in weight. The increase of the hardness with the milling time is observed only in the composite bars. It seems that a better dispersion of MWCNT is obtained as the milling time increases from 6 to $10 \mathrm{~h}$, resulting in better properties. When compared to un-reinforced bars, the hardness of the samples 6061-1CNT-6h, 6061-2CNT-6h, 6061-1CNT-10h and 6061-2CNT-10h, increased by $20,30,57$ and $68 \%$ respectively. This increase is remarkable, but surprisingly, after heat treatment, an additional contribution from precipitation hardening could not be observed at T4 and T6 conditions for any sample. In some cases, the hardness even decreased after heat treatment. Similar behavior has been observed for AA6063 alloy [18], but only when reinforced by CNT. In this reference work, the composites were not produced by HEBM as in the present work. It seems that microstructural benefits resulted from HEBM as strain hardening and/or the development of a subgrain structure [24] that could manifest in the as-extruded condition could be lost during solution heat treatment, which could compensate the precipitation hardening obtained by heat treatment. Furthermore, the presence of hard reinforcing phases in ductile matrices generates internal stresses [25] that can accelerate the precipitation kinetics. High defects concentration produced by HEMB process [24] can account for similar behavior, due to the higher concentration of favorable nucleation sites for precipitates. Under such conditions, heat treatment procedures applicable to commercial alloys that are produced by conventional thermo mechanical processing, could lead to overaging of the composites produced by HEBM.

As far as precipitation hardening in HEBM processed materials is concerned, the literature also point out that the grain refinement reduces the potential for precipitation hardening in some alloys [3,25-26]. In this case, when the grain becomes too small, the volume of the grains (were precipitation would be effective for hardening) diminishes in comparison to the grain boundary area. As a consequence, precipitates could form at grain boundaries, were precipitation is more favorable, but less effective for hardening. This is another aspect to be investigated in order to assess the behavior of CNT reinforced aluminum alloys produced by HEBM during subsequent precipitation hardening heat treatments.

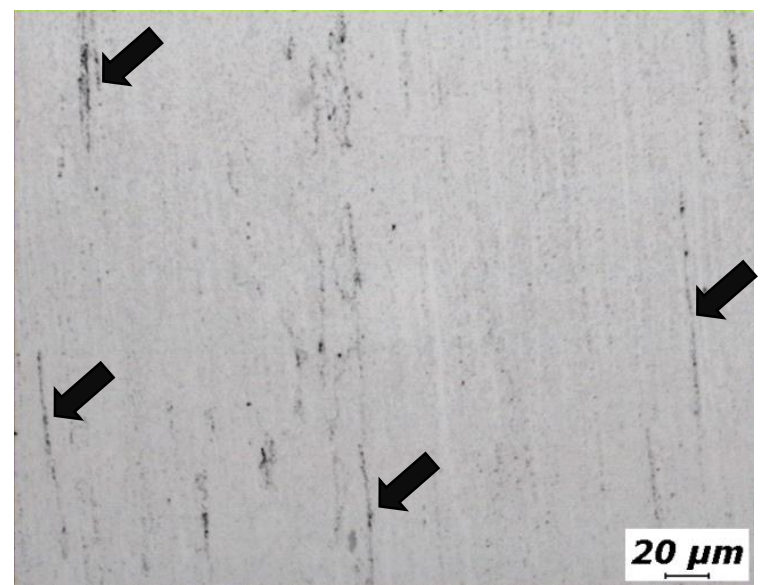

Figure 4. Optical micrograph of sample containing $2 \%$ of MWCNT milled for $10 \mathrm{~h}(6061-2 \mathrm{CNT}-10 \mathrm{~h})$, in the longitudinal T4 condition. Some of the voids originating after solution heat treatment are indicated by arrows.

\footnotetext{
* Technical contribution to the $69^{\text {th }}$ ABM International Annual Congress and to the ENEMET, July $21^{\text {st }}-25^{\text {th }}$, 2014, São Paulo, SP, Brazil.
} 


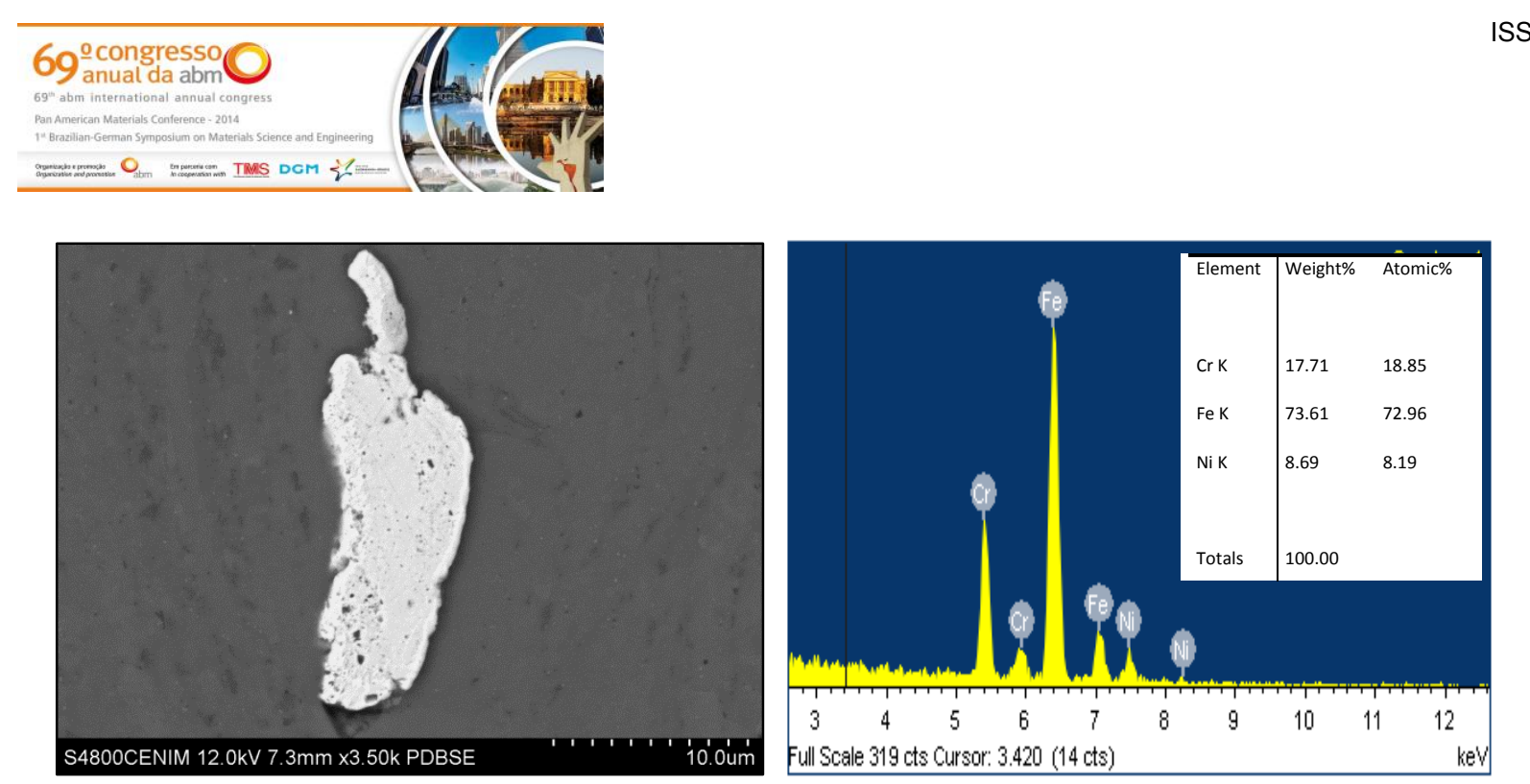

Figure 5. Scanning electron micrograph of the sample 6061-NR-6h, in the longitudinal as-extruded condition. The particle in the center of the micrograph refers to stainless steel contamination from tue milling vials, as confirmed by EDS microanalysis in the left.

Table 3. Vickers microhardness values obtained in the bars, in AE, T4 and T6 conditions

\begin{tabular}{lccc}
\hline \multicolumn{1}{c}{ Sample } & $\mathrm{AE}$ & $\mathrm{T} 4$ & $\mathrm{~T} 6$ \\
\hline 6061-NR-6h & $72,3 \pm 3,1$ & $54,7 \pm 6,1$ & $71,7 \pm 2,9$ \\
\hline $6061-1 \mathrm{CNT}-6 \mathrm{~h}$ & $86,0 \pm 3,5$ & $68,7 \pm 3,6$ & $75,3 \pm 4,9$ \\
\hline $6061-2 \mathrm{CNT}-6 \mathrm{~h}$ & $93,3 \pm 0,6$ & $79,0 \pm 4,6$ & $79,3 \pm 3,8$ \\
\hline $6061-N R-10 \mathrm{~h}$ & $69,7 \pm 1,9$ & $53,5 \pm 4,1$ & $61,5 \pm 4,3$ \\
\hline $6061-1 \mathrm{CNT}-10 \mathrm{~h}$ & $113,5 \pm 4,4$ & $100,3 \pm 3,2$ & $103,3 \pm 6,2$ \\
\hline $6061-2 \mathrm{CNT}-10 \mathrm{~h}$ & $121,3 \pm 1,2$ & $119,7 \pm 0,6$ & $113,7 \pm 3,1$ \\
\hline
\end{tabular}

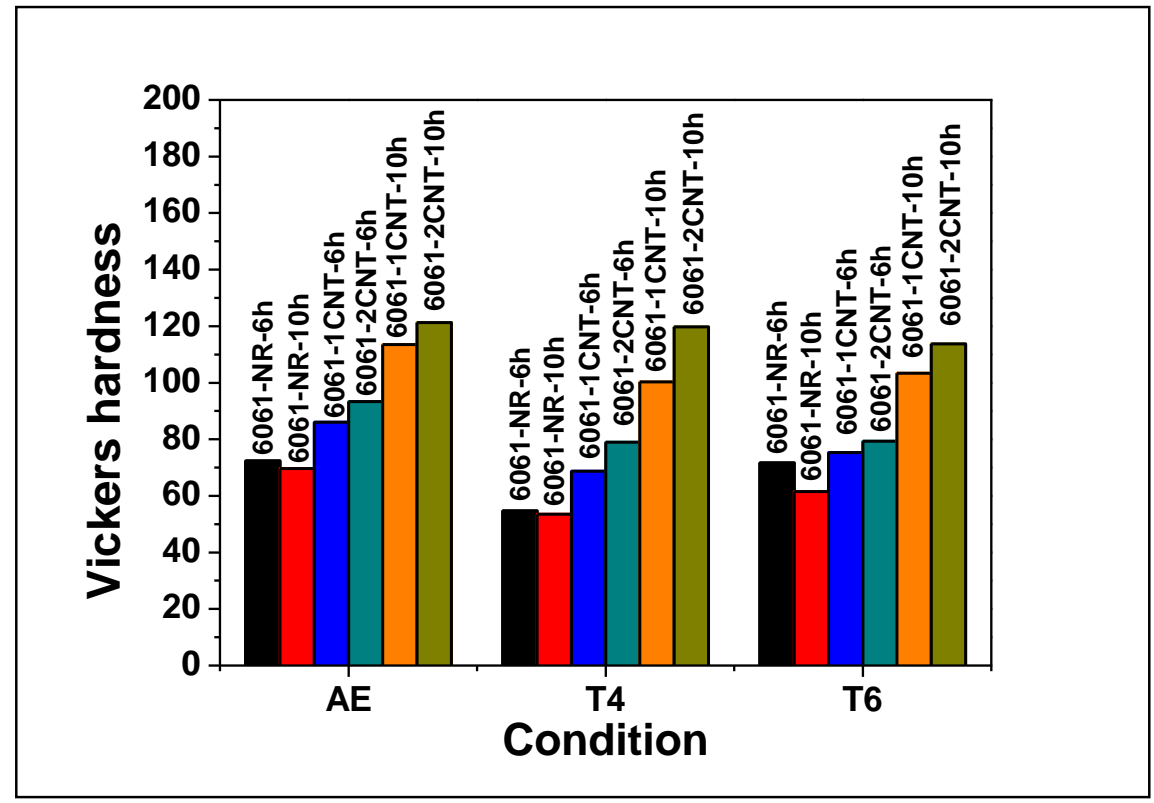

Figure 6. Microhardness measurements of the composite and non-reinforced bars produced, at the as-extruded, T4 and T6 conditions.

\section{CONCLUSION}

AA6061 alloy reinforced by MWCNT composites were succesfull produced by HEBM - hot extrusion processing route. The benefits of MWCNT to the alloy strength, as verified by microhardness measurements, were remarkable. Vickers hardness increased by 20 and $30 \%$ with additions of 1,0 and 2,0\% of MWCNT (in weight) respectively, when comparing to the unreinforced alloy produced by the same route.

\footnotetext{
* Technical contribution to the $69^{\text {th }} A B M$ International Annual Congress and to the ENEMET, July $21^{\text {st }}-25^{\text {th }}$, 2014, São Paulo, SP, Brazil.
} 


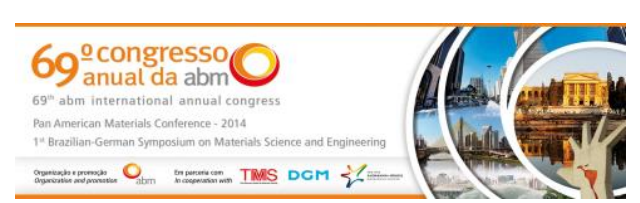

The benefits were even higher when the milling time was increased from 6 to $10 \mathrm{~h}$, resulting in hardness increments by 57 and $68 \%$ for the same MWCNT additions. A better dispersion of nanotubes is supposed to occur with the higher milling time, resulting in higher strength of the composite.

The combination of MWCNT dispersion and alloy precipitation to the composite hardening was not observed in the present work, at least with the heat treatment procedure recommended for the commercial alloy. It seems that microstructural benefits arising from HEBM process could be lost during solution heat treatment, mainly for long periods ( $1 \mathrm{~h}$ in the present work). Furthermore, both the precipitation kinetics and grain boundary precipitation could be accelerated in fine grain HEBM composites, making conventional heat treatment procedures of commercial alloys inapplicable for such materials. However, the strength level reached in the asextruded condition is already very promising for structural applications.

\section{Acknowledgments}

The authors are very thankful to researchers at Associated Laboratory for Sensors and Materials from the National Institute for Space Research (LAS-INPE - Brazil), for the Raman Spectroscopy analysis. Dilermando Nagle Travessa is very thankful to FAPESP for the founding related to an internship at CENIM-CSIC - Spain (process no. 2012-07831-2).

\section{REFERENCES}

1 Thostenson ET, Renb Z, Choua TW. Advances in the science and technology of carbon nanotubes and their composites: a review. Composite Science and Technology. $2001 ; 61: 1899-1912$.

2 Paradise M, Goswami T. Carbon nanotubes - Production and industrial applications. Materials. \& Design. 2007;28:1477-89.

3 Choi HJ, Shin JH, Bae DH. Grain size effect on the strengthening behavior of aluminum-based composites containing multi-walled carbon nanotubes. Composites Science and Technology. 2011;71:1699-1705.

4 Poirier D, Gauvin R, Drew RAL. Structural characterization of a mechanically milled carbon nanotube/aluminum mixture. Composites: Part A. 2009;40:1482-89.

5 Esawi AMK, Morsi K, Sayed A, Gawad AA, Borah P. Fabrication and properties of dispersed carbon nanotube-aluminum composites. Materials Science and Engineering A. 2009;508:167-173.

6 Choi HJ, Kwon GB, Lee GY, Bae DH. Reinforcement with carbon nanotubes in aluminum matrix composites. Scripta Materialia. 2008;59:360-363.

7 Deng C, Wang D, Zhang XX, Li AB. Processing and properties of carbon nanotubes reinforced aluminum composites. Materials Science and Engineering A. 2007;444:138145.

8 Bustamante RP, Guel IE, Madrid PA, Yoshida MM, Ramírez JMH, Sánchez RM. Microstructural characterization of Al-MWCNT composites produced by mechanical milling and hot extrusion. Journal of Alloys and Compounds. 2010;495:399-402.

9 George R, Kashyap KT, Rahul R, Yamdagni S. Strengthening in carbon nanotube/aluminium (CNT/AI) composites. Scripta Materialia. 2005;53:1159-63.

10 Morsi K, Esawi AMK, Lanka S, Sayed A, Taher M. Spark plasma extrusion (SPE) of ball-milled aluminum and carbon nanotube reinforced aluminum composite powders. Composites: Part A. 2010;41:322-326.

11 Zhong R, Cong H, Hou P. F abrication of nano-Al based composites reinforced by single-walled carbon nanotubes. Carbon. 2003;41:848-851.

\footnotetext{
* Technical contribution to the $69^{\text {th }}$ ABM International Annual Congress and to the ENEMET, July $21^{\text {st }}-25^{\text {th }}$, 2014, São Paulo, SP, Brazil.
} 


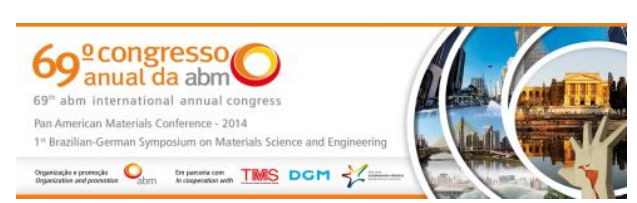

12 Kwon H, Park DH, Silvain JF, Kawasaki A. Investigation of carbon nanotube reinforced aluminum matrix composite materials. Composites Science and Technology. 2010;70:546-550.

13 Liao J, Tan M, Sridhar I. Spark plasma sintered multi-wall carbon nanotube reinforced aluminum matrix composites. Materials and Design. 2010;31:S96-S100.

14 Laha T, Agarwal A. Effect of sintering on thermally sprayed carbon nanotube reinforced aluminum nanocomposite. Materials Science and Engineering A. 2008;480:323-332.

15 Wang L, Choi H, Myoung J, Lee W. Mechanical alloying of multi-walled carbon nanotubes and aluminium powders for the preparation of carbon/metal composites. Carbon. 2009;47:3427-33.

16 Deng CF, Zhang XX, Wang DZ, Lin Q, Li A. Preparation and characterization of carbon nanotubes/aluminum matrix composites. Materials Letters. 2007;61:1725-28.

17 Deng CF. Zhang XX, Wang DZ, Ma XY. Calorimetric study of carbon nanotubes and aluminum. Materials Letters. 2007;61:3221-23.

18 Kondoh K, Fukuda H, Umeda J, Imai H, Fugetsu B. Microstructural and mechanical behavior of MWCNTs reinforced Al-Mg-Si alloy composites in aging treatment. Carbon 2014; accepted manuscript - doi 10.1016/j.carbon.2014.01.013.

19 Aerospace Material Specification. Society of Automobile Engineers - SAE. AMS-QQ-A200/8: Aluminum Alloy 6061, Bar, Rod, Shapes,Tube, and Wire, Extruded. SAE International; 2007.

20 Aerospace Material Specification. Society of Automobile Engineers - SAE AMS2772E: Heat Treatment of Aluminum Alloy Raw Materials. SAE International; 2008.

21 Dresselhaus MS, Dresselhaus G, Saito R, Jorio A. Raman spectroscopy of carbon nanotubes. Physics Reports. 2005;409:47-99.

22 Antunes EF, Lobo AO, Corat EJ, Trava-Airoldi VJ, Martin AA, Veríssimo C. Comparative study of first- and second order Raman spectra of MWCNT at visible and infrared laser excitation. Carbon. 2006;44:2202-11.

23 MacKenzie DS, Totten GE. Analytical characterization of aluminium, steel, and superalloys. Boca Raton: CRC Press - Taylor \& Francis Group; 2006.

24 Suryanarayana C. Mechanical alloying and milling. Progress in Materials Science. $2001 ; 46: 1-184$.

25 Arakawa S, Hatayama T, Matsugi K, Yanagisawa O. Effect of heterogeneous precipitation on age-hardening of $\mathrm{Al}_{2} \mathrm{O}_{3}$ particle dispersion $\mathrm{Al}-4 \%$ mass $\mathrm{Cu}$ composite produced by mechanical alloying. Scripta Materialia. 2000;42:755-760.

26 Corrochano J, Lieblich M, Ibáñez J. On the role of matrix grain size and particulate reinforcement on the hardness of powder metallurgy Al-Mg-Si/MoSi 2 composites. Composites Science and Technology. 2009;69:1818-24.

* Technical contribution to the $69^{\text {th }}$ ABM International Annual Congress and to the ENEMET, July $21^{\text {st }}-25^{\text {th }}, 2014$, São Paulo, SP, Brazil. 